Palabra Clave (La Plata)

ISSN: 1853-9912

palabraclave@fahce.unlp.edu.ar

Universidad Nacional de La Plata

Argentina

\title{
Coleções de livros de bolso no Brasil: notas sobre a Biblioteca Universal Popular
}

\author{
Ribeiro, Ana Elisa; Karam, Sérgio \\ Coleções de livros de bolso no Brasil: notas sobre a Biblioteca Universal Popular \\ Palabra Clave (La Plata), vol. 9, núm. 2, 2020 \\ Universidad Nacional de La Plata, Argentina \\ Disponible en: http://www.redalyc.org/articulo.oa?id=350562513011 \\ DOI: https://doi.org/10.24215/18539912e084
}

Esta obra está bajo una Licencia Creative Commons Atribución-NoComercial-Compartirlgual 4.0 Internacional. 
Dossier: Catálogos y colecciones editoriales en Latinoamérica: abordajes teóricos, históricos y materiales

\section{Coleções de livros de bolso no Brasil: notas sobre a Biblioteca Universal Popular}

Pocket books collections in Brazil: notes on Biblioteca Universal Popular

Ana Elisa Ribeiro

Centro Federal de Educação Tecnológica de Minas Gerais.

Programa de Pós-Graduação em Estudos de Linguagens,

Brasil

anadigital@gmail.com

Sérgio Karam

Universidade Federal do Rio Grande do Sul. Programa de

Pós-Graduação em Letras, Brasil

sbkaram@uol.com.br
DOI: https://doi.org/10.24215/18539912e084

Redalyc: http://www.redalyc.org/articulo.oa? id $=350562513011$

Recepción: 04 Febrero 2020

Aprobación: 17 Marzo 2020

\section{Resumo:}

Estão em foco, neste trabalho, ao menos dois elementos da edição importantes para a compreensão dos modos de produção e circulação dos livros no Brasil: as noções de "livro popular" e de "livro de bolso", ambas estreitamente relacionadas entre si e também a estratégias de produção e venda, formatos, design e certos gêneros, aqui no sentido de gêneros literários ou gêneros "de livraria”. Trataremos aqui, para fins de discussão conceitual, mas também para uma análise de práticas editoriais, da Biblioteca Universal Popular, coleção de livros de bolso publicada no país entre 1963 e 1968 pela Editora Civilização Brasileira, uma das mais importantes casas editoriais em atividade naquele momento. Outro aspecto relevante do presente estudo é a recomposição do catálogo da referida coleção, que representa uma das muitas tentativas de editoras brasileiras de acercar-se ao mercado dos livros de bolso por meio da edição de livros de baixo custo e ampla circulação. A coleta e a organização das informações aqui elencadas deram-se com base em consultas a bibliotecas particulares e a diversos sites, especialmente o acervo on-line da Fundação Biblioteca Nacional e a Estante Virtual.

PalaVras-chave: Biblioteca Universal Popular, Editora Civilização Brasileira, Produção editorial, Livros de bolso, Coleções.

\section{ABstRACT:}

In this work, we have focused in at least two elements of edition that are crucial to the understanding of the modes of production and the circulation of books in Brazil. These are the notions of "popular book" and "pocket book", both closely related to each other and also to production and sales strategies, book formats, book design and certain literary genres or "bookstore" genres. For the purposes of conceptual discussion and analysis of editorial practices, we will deal here, with the Biblioteca Universal Popular (Universal Popular Library). This is a collection of paperbacks published in Brazil between 1963 and 1968 by Editora Civilização Brasileira, one of the most important publishing houses in activity at that time. Another relevant aspect of the present study is the recomposition of the catalog of this collection, which represents one of the many attempts of Brazilian publishers to approach the pocket book market through the edition of low cost books with a wide circulation. The collection and organization of the information presented here are based on investigations in private libraries and in various websites, especially in the online collection of Fundação Biblioteca Nacional and in the website of Estante Virtual.

KeYwords: Biblioteca Universal Popular, Civilização Brasileira, Publishing Company, Editorial production, Pocket books, Collections.

\section{INTRODUÇÃo: LIVROS DE BOLSO, UM SÉCULO OU MEIO MILÊNIO}

Data de pelo menos um século uma das perguntas que não se calam no Brasil, e sem resposta - ou, pior, sem solução: Somos um país de leitores? Segundo Alessandra El Far (2006), a questão já incomodava a elite intelectual e editorial do Rio de Janeiro no início do século XX, isto é, cerca de cem anos depois que a imprensa 
aportou, oficialmente, em solo brasileiro. A aparente movimentação em livrarias de rua na então capital do país, o Rio de Janeiro, fazia crer, ao menos ao escritor João do Rio, que, sim, o Brasil era um país de leitores, muito embora o cronista só pudesse observar o espaço ao seu redor. De opinião radicalmente contrária, o poeta Olavo Bilac considerava que não, não éramos leitores, e acreditava nisso fundamentado nas dificuldades que seus contemporâneos escritores tinham de vender e esgotar tiragens de seus livros, além dos dados já existentes sobre o analfabetismo, que imperava naquele momento histórico (e ainda persiste, hoje) no país.

A ampliação do acesso à leitura e ao livro no Brasil, portanto, parecem ocorrer na virada do século XIX para o XX, em decorrência de aspectos socioeconômicos, históricos e tecnológicos complexos e interligados, computando-se então o esforço dos editores e a existência de coleções populares, que significavam, principalmente, preços reduzidos e temas de interesse mais amplo, sendo vendidos em cafés e bancas de jornal. 1 Nessa virada, aparece o "livro de bolso" como sinônimo desse tipo de objeto produzido e vendido a menor custo, seja ele uma obra-prima da literatura mundial ou um best-seller de autoajuda sem tanto prestígio.

A contar da história oficial da produção editorial no Brasil, isto é, do século XIX em diante, o livro de bolso, como formato que é, e também estratégia, sempre se confundiu com o "livro popular", uma vez que tanto seu preço quanto as formas de acesso a ele são, em tese, diferenciados justamente para alcançar um público maior. Ainda hoje, esses livros são encontrados em bancas e outros espaços mais acessíveis e mais numerosos do que as livrarias, em especial na forma de romances "água com açúcar”, embora várias editoras brasileiras, nos últimos vinte ou trinta anos, tenham retomado e reforçado suas coleções de bolso, inclusive publicando versões mais baratas dos títulos canônicos de seu catálogo.

A introdução mais veemente do livro de bolso no Brasil, ${ }^{2}$ é atribuída a iniciativas gaúchas, em especial à da coleção "Biblioteca Econômica" (Castro, 2005; Hallewell, 2005), lançada na década de 1880 pela Livraria Americana, editora sediada na cidade de Pelotas (interior do Rio Grande do Sul), responsável também por muita pirataria; e, mais adiante, à da Livraria do Globo, de Porto Alegre, fundada primeiro como papelaria, em 1883, e, após muitas mudanças, tornada Editora Globo, a partir de 1948. A Globo empreendeu, ao longo de décadas, várias tentativas de emplacar coleções de bolso, tais como a "Coleção Globo", primeira de abrangência nacional; mais tarde a "Coleção Tucano" (1943-1945); e, entre 1959 e 1969, a "Coleção Catavento", todas elas consideradas fracassos comerciais (Souza e Crippa, 2014).

No século XX, várias editoras, em especial no Rio de Janeiro e em São Paulo, mas também em Belo Horizonte, lançaram coleções de bolso com o objetivo de popularizar o acesso ao livro, sempre em consonância com contextos de expansão da escolarização e ampliação da capacidade de ler da população. Segundo Souza e Crippa (2014), dois casos merecem destaque: as Edições de Ouro, pioneiras na produção de uma coleção de livros de bolso de padrão mais alto e promessa de texto integral, nos anos 1960, embora dela estivessem ausentes livros inéditos ou de contemporâneos; e a Tecnoprint (depois Ediouro), nos anos 1970, com sucesso na comercialização de livros baratos e de qualidade. Mais tarde, já nos anos 1980, a editora Brasiliense foi responsável por um sucesso editorial de prestígio até hoje, a "Coleção Primeiros Passos". ${ }^{3}$ Contemporânea às Edições de Ouro, a BUP, objeto deste trabalho, publicada pela editora Civilização Brasileira, também se embrenhou por este caminho.

Os livros em formato de bolso enfrentaram forte preconceito do consumidor brasileiro, que sempre os associava a livros de baixa qualidade, feitos com papel ruim, sem cuidado estético-gráfico, com más traduções ou textos alterados, elementos que realmente caracterizavam os livros "populares" de várias casas editoriais mundo afora e no Brasil. ${ }^{4}$ Essa percepção do leitor podia incluir também um preconceito de classe, isto é, a associação entre livros de bolso e livros para pessoas de baixo poder aquisitivo. Foi o esforço das Edições de Ouro que mexeu nessa percepção dos leitores, a partir de projetos populares feitos com apuro. Depois dela, a Tecnoprint e, finalmente, a L\&PM, de Porto Alegre, que, a partir dos anos 1990, lançou no mercado brasileiro a coleção de pocket books mais ampla e de maior sucesso existente até hoje (Souza e Crippa, 2014). Em todos os casos, o custo/preço baixos e a oferta de muitos títulos foram impulsos para as coleções, além da existência dos pontos de venda para além das livrarias, isto é, as bancas de jornal, farmácias e outros tipos 
de comércio que acabavam também por concorrer para o estabelecimento do preconceito dos consumidores mais "seletivos".

É interessante lembrar, no entanto, que a história do livro de bolso no Brasil (e nossa apropriação desse objeto tecnológico) ocupa um quinto da história do livro de bolso no mundo ou, melhor dizendo, na Europa. Afora a patente exclusão da história do livro no mundo, que computaria nossos (des)conhecimentos sobre a China, por exemplo, ou sobre os habitantes originais de territórios como o atual México, é importante recobrar uma história do livro segundo a qual é Aldo Manuzio, editor, tipógrafo e livreiro veneziano do século $\mathrm{XV}$, o autor da ideia de produzir livros de bolso ou Libelli portatiles informam enchiridii (conforme, segundo afirma Satué, lia-se num catálogo de livros de 1503) (Calasso, 2014; Satué, 2004).

Segundo Enric Satué (2004) estão entre as "contribuições excepcionais" de Manuzio e, até hoje, pouco alteradas:

A letra cursiva, o formato de bolso, o livro ilustrado, o livro de texto, o impulso definitivo aos tipos de fundição do estilo românico, a página dupla considerada como unidade formal, a capa de couro sobre papelão, a lombada quadrada, a gravação de ouro laminado aquecido, as coleções temáticas, os catálogos, os conselhos editoriais e inúmeras outras coisas são obra dele. (Satué, 2004, p. 23).

O livro de bolso é considerado obra do "instinto comercial" (Satué, 2004, p. 33) do tipógrafo italiano, que teria ainda inventado o que Satué afirma ser a "coleção de bolso mais antiga do mundo", cujo objetivo era levar às mãos de estudantes e de interessados em geral obras greco-romanas clássicas. A invenção do tipo itálico (ou aldino ou, mais tarde, grifo) ${ }^{5}$ teve relação direta com a invenção do livro em formato menor, já que era necessário que mais letras coubessem nas linhas mais curtas. O livro de bolso, então, é considerado uma invenção de "caráter pragmático", assim como uma "conclusão brilhante, eficaz e competitiva sem par", "genial” (Satué, 2004, p. 113). Para Calasso (2014, p. 172), Manuzio é o ousado editor do livro "mais bonito que se tem impresso até nossos dias", o Hypnerotomachia Poliphili.

Em relação às suas dimensões, o pequeno livro aldino foi resultado de elementos percebidos pelo editor, sendo um deles e o principal a popularidade de outros livros de formato pequeno, tais como os devocionários, breviários e livros de horas (Satué, 2004). Passou-se então do fólio - mais tradicional e solene - ao in-oitavo, que media aproximadamente $10 \times 15 \mathrm{~cm}$ (o tamanho de uma foto do século XX, já rara quando impressa no século XXI).

Satué (2004) compara o livro de bolso de padrão aldino com os livros da editora Penguin, da Inglaterra, que, séculos depois, para aproveitar melhor e mais racionalmente grandes formatos de papel, altera as medidas do livro de bolso para $11 \times 18 \mathrm{~cm}$ e as consagra. Outras editoras seguiram esse exemplo e também foram bemsucedidas com obras de formato e preço populares, entre elas a Espasa-Calpe Argentina e sua "Colección Austral” ${ }^{6}$ e a Alianza Editorial, ambas em língua espanhola, além da iniciativa francesa de Henri Filipacchi e sua Librairie Générale Française, que lançou a coleção "Le Livre de Poche” em $1953 .{ }^{7}$

Consagrar o livro ou uma coleção como "popular" tem sido uma tentativa das editoras, nem sempre exitosa. Mas o que se entende por "popular" em um país cuja formação de leitores é considerada insuficiente ou precária? A despeito de serem contextos muito diferentes, cabe aqui uma adaptação da pergunta de Chartier (2004): Será que os meios populares têm muito peso entre os possuidores e compradores de livros? A questão do historiador diz respeito ao século XVI, na França do Antigo Regime, mas e quanto ao Brasil dos séculos XIX e XX? Trata-se, certamente, de questão que exige fôlego e na qual não vamos nos debruçar aqui, embora valha sua menção.

Néstor García Canclini (2013), pensando desde a América Latina, ao discutir as noções de "popular”, "popularidade", "povo", “cultura de massas", "subalternidade”, entre outras, traz à tona uma questão que pode se relacionar às práticas editoriais ligadas às coleções ditas "populares", do ponto de vista de quem as propóe e produz. Baseando-nos em García Canclini, podemos pensar que as coleções populares de livros, que andam muito juntas às concepções de livros de bolso no Brasil, atuam na direção do pretenso ou pretendido leitor, 
isto é, as instituições e editoras pretendem produzir algo que seja "acessível" ao povo, tanto do ponto de vista do preço quanto do conteúdo, algo que "caia no gosto" popular, a fim de que se transforme em um sucesso de vendas. Em raras ocasiões o "popular" se refere a algo que venha do povo. Dessa forma, historicamente em nosso país, coleções de bolso são criadas e lançadas, raramente obtendo o sucesso esperado, muito embora essa relação já tenha mudado do fim do século XX para o início do XXI, quando casas editoriais mais jovens começaram a se sustentar pelas coleções de livros de relativo baixo custo.

\section{A Biblioteca Universal Popular}

Uma coluna não assinada no Correio da Manhã de 18 de maio de 1963 anunciava que uma "nova editora" havia sido fundada no então estado da Guanabara. Tratava-se da Biblioteca Universal Popular (BUP), que se dedicaria a editar "livros de bolso com séries sobre ficção brasileira e estrangeira, policial e aventuras, dicionários e humorismo, teatro, clássicos, ciências sociais e utilidades, literatura infantil e de divulgação", conforme se pode ler na referida coluna (acessível pela hemeroteca da Biblioteca Nacional). Entre os diretores da "nova editora” estavam Ênio Silveira (Diretor Presidente) e Mário da Silva Brito (Diretor Editorial), nomes ligados à Editora Civilização Brasileira, uma das mais importantes e ativas editoras brasileiras àquela altura.

Fundada em 1929 e incorporada, três anos depois, à Companhia Editora Nacional do editor Octalles Marcondes Ferreira, a Civilização Brasileira foi aos poucos se tornando independente e crescendo em importância no mercado editorial brasileiro, capitaneada por Ênio Silveira, que em 1963 - ano do lançamento da BUP - assumiu o controle total da empresa. Sob seu comando, a Civilização publicou importantes coleções de literatura brasileira (Vera Cruz) e de literatura estrangeira (Biblioteca do Leitor Moderno), bem como inúmeras outras coleções na área das ciências humanas e afins (Sociologia, História, Antropologia, Psicanálise, entre outras).

Quer a consideremos uma editora independente ou um selo ou braço da Civilização Brasileira, o fato é que a BUP representou mais uma tentativa de se publicar livros a baixo custo no Brasil e assim tornálos acessíveis a um público mais amplo. Para isso, contou com o apoio explícito de um banqueiro de boas intenções, conforme se pode ler no texto que acompanhava cada volume da coleção, pelo menos nos primeiros anos:

A produção deste livro de qualidade literária e de grande valor cultural ou recreativo, mas de preço acessível a todas as bolsas, foi conseguida graças à colaboração de José Luiz de Magalhães Lins, um banqueiro a serviço do Brasil e dos interesses nacionais. (in: Contos norte-americanos, vol. 1 da BUP, 1963).

Novamente no Correio da Manhã, em 24 de julho de 1963, desta vez na coluna "Escritores e Livros", assinada por José Condé, anunciam-se os oito primeiros volumes da BUP, a saber:

O conto norte-americano, antologia; A morte de Ivã Ilitch, novela de Tolstoi; Lucíola, de José de Alencar; Capitalismo do século vinte, de E. Varga; A data fatal, novela policial de Philip MacDonald; Poemas de amor, de Castro Alves (com introdução e notas de Jamil Almansur Haddad); Memórias de um trapaceiro, de Sacha Gitry; e Desaforismos, livro de humor de Mário da Silva Brito. Após estes primeiros volumes, a BUP editará, por mês, pelo menos dois títulos novos (Correio da Manhã, 24 jul. 1963).

Para se tiver uma ideia da tiragem destes livros, se é que estes números valem para todos os títulos da BUP, vamos recorrer mais uma vez ao Correio da Manhã, que, na coluna não assinada "Livros da semana", de 16 de novembro de 1963, informa a seus leitores que Mário da Silva Brito, Diretor Editorial da BUP, havia revelado num programa de televisão que "da edição da Metamorfose, de Kafka (vol. 9 da BUP - série Ficção Estrangeira), venderam-se em poucos dias dez mil exemplares", uma tiragem bastante impressionante. Além das tiragens elevadas, registre-se que num período de cinco meses, de julho a dezembro de 1963, a BUP lançou no mercado 21 títulos, uma média de quatro títulos por mês. Interessante observar, num texto assinado por 
Iderval Garcia no mesmo Correio da Manhã, em 15 de dezembro de 1963, o tom preconceituoso em relação aos livros de bolso: "É verdade que essa coleção da BUP lança livros de bolso, a preços populares, mas de grande valor cultural, apresentando, mesmo, obras de autores consagrados pelos críticos e pela própria história - os clássicos" (Correio da Manhã, 15 dez. 1963). Na figura 1, podemos ver o anúncio no periódico da BUP:

FIGURA 1

Anúncio da BUP.

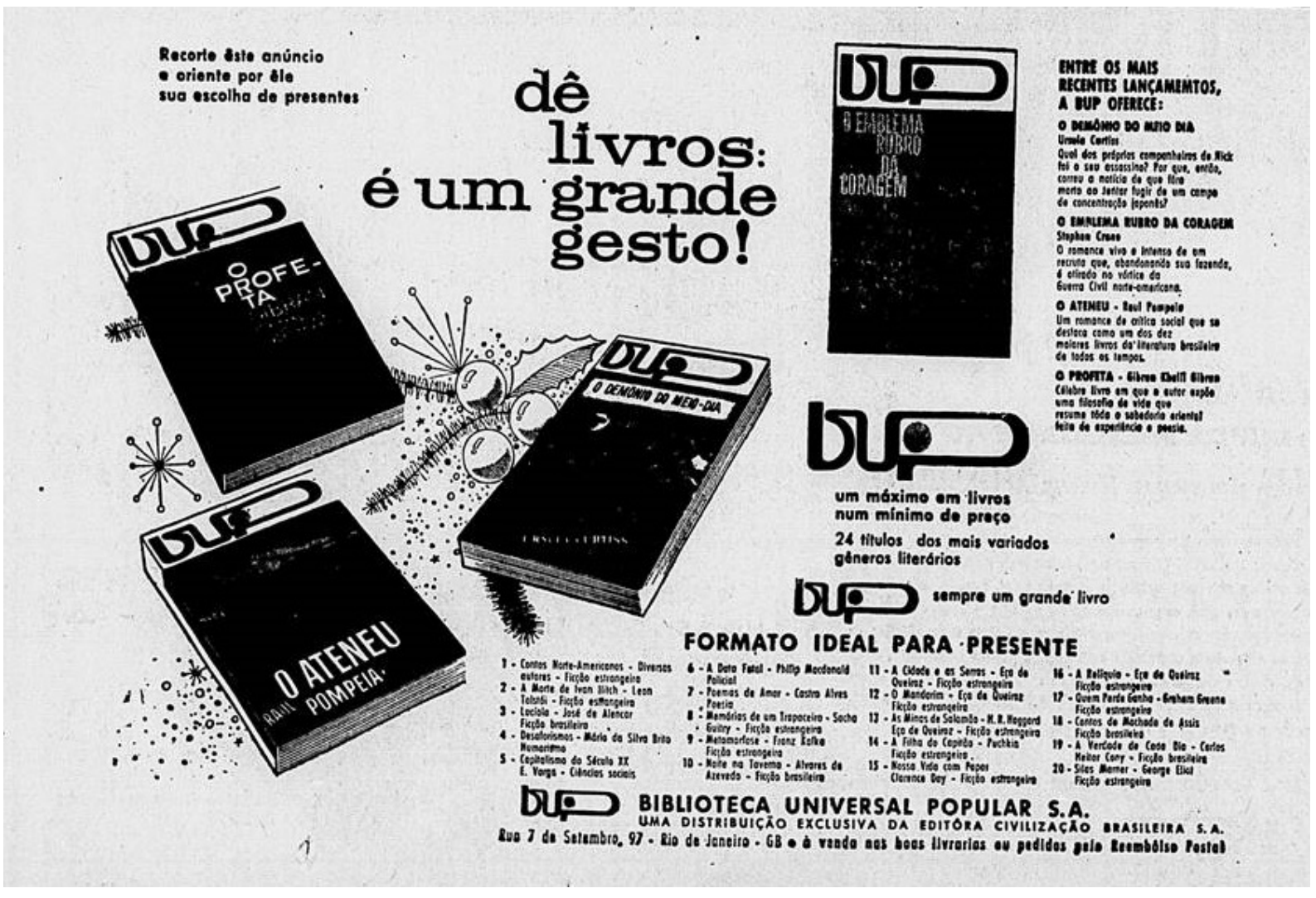

Fonte: Correio da Manhã, dez. 1963. (http://memoria.bn.br/DocReader/089842_07/47002)

Assim como a gaúcha L\&PM faria muitos anos depois com sua coleção pocket, a BUP também foi buscar parte de seus títulos no catálogo geral da editora, no seu caso o rico catálogo da Civilização Brasileira. Afora o formato de 10,5 x $17 \mathrm{~cm}$, comum a todos os títulos, os livros da BUP podiam ser muito diferentes entre si, no que se refere a capa, número de páginas de cada título, preço ou gênero literário ou editorial. Nela podiamse encontrar, por exemplo, livros sobre os cuidados com hortas e jardins bem como livros de divulgação científica, embora a maioria dos títulos privilegiasse mesmo a literatura de ficção, nacional ou estrangeira. As séries a que os títulos pertenciam eram identificadas na capa do volume logo abaixo do logotipo da coleção, como "ficção estrangeira" ou "aventura", desta forma conferindo alguma organização à coleção mais ampla.

$\mathrm{Na}$ seguinte figura 2 podemos olhar a composição dos primeiros títulos da BUP. 
FIGURA 2

Primeiros 24 volumes da BUP em página interna de volume.

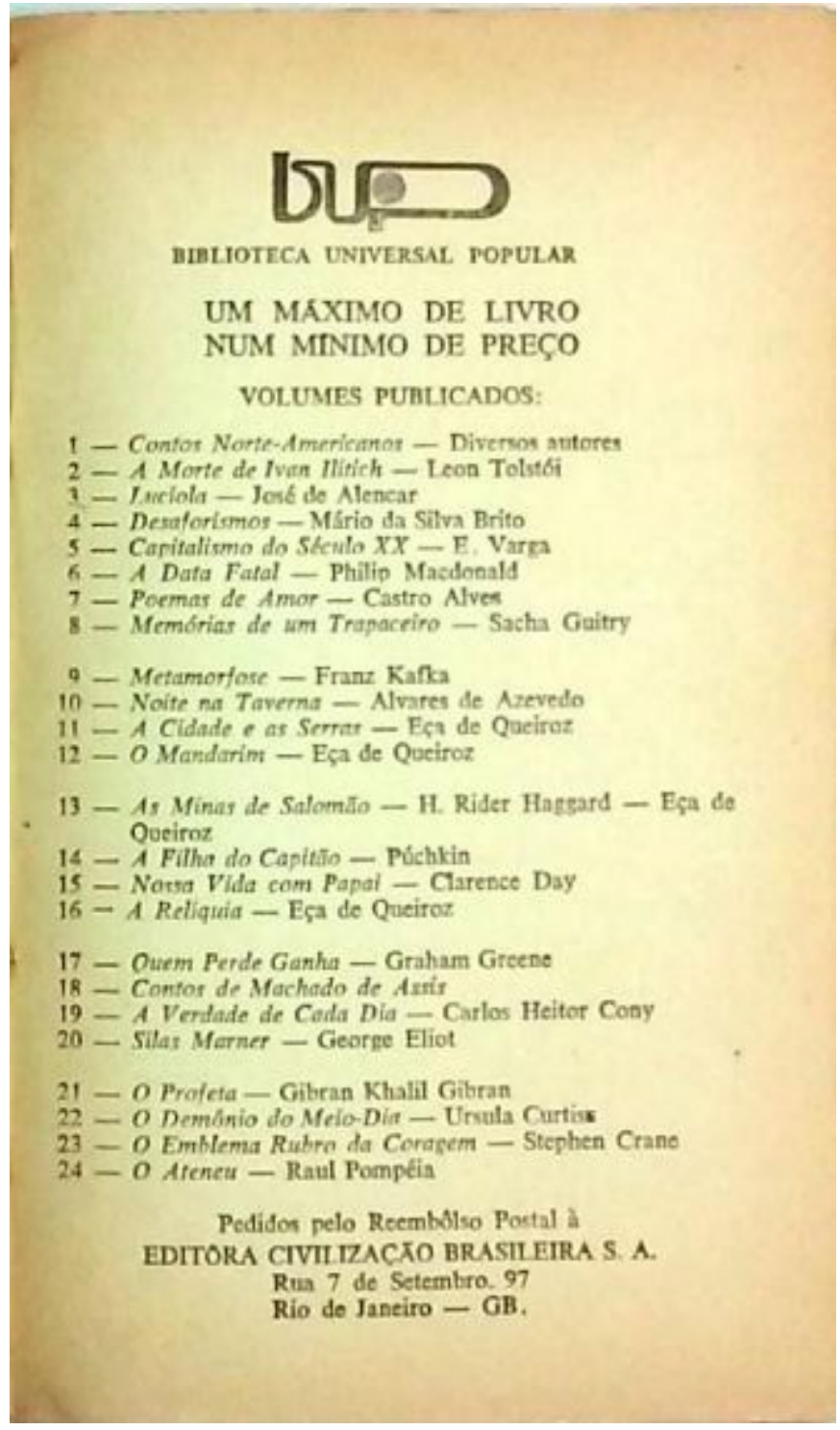

Fonte: Fac-símile dos autores.

A fim de recuperar parcialmente a história material da BUP, passamos à recomposição de seu catálogo, com base na investigação que partiu de nosso acervo particular, mas principalmente do acervo da Biblioteca Nacional e do "sebo" Estante Virtual, ambos on-line. O acervo privado oferece uma pista da extensão de uma coleção que chega a dezenas de títulos, embora não tenha sido possível precisar todos. É comum encontrar, no percurso de pesquisa, problemas que, juntos, levam à extrema dificuldade de localizar determinada obra: sem registro nas orelhas de outros livros da coleção, inexistência nos acervos consultáveis, possível não publicação, ainda que um título tenha sido anunciado como lançamento, entre outros. A história dos livros, neste caso, de uma coleção em muito se parece com a história humana, em suas imprecisões e omissões. Vejamos a recomposição de um catálogo possível da BUP no quadro 1. 
QUADRO 1

BUP - Editora Civilização Brasileira

\begin{tabular}{|c|c|c|c|c|}
\hline $\mathrm{N}^{0}$ & Título & Autor/a & Tradutor/a & $\begin{array}{c}\text { Ano de } \\
\text { publicacão }\end{array}$ \\
\hline 1 & $\begin{array}{l}\text { Contos norte-americanos } \\
\text { - antologia }\end{array}$ & \begin{tabular}{lr}
\multicolumn{2}{l}{ Washington Irving, } \\
Edgar Allan Poe, \\
Herman Melville, \\
Frank R. Stockton, \\
Mark Twain, Bret \\
Harte, Henry James, \\
O. Henry, Sherwood \\
Anderson, Dorothy \\
Parker, James \\
Thurber, Stephen \\
Vicent Benet, Ernest \\
Hemingway, John \\
Steinbeck, Erskine \\
Caldwell e & William \\
Saroyan
\end{tabular} & $\begin{array}{ll}\text { Alfredo } & \text { Mesquita, } \\
\text { Antonio Candido, Décio } \\
\text { de Almeida Prado e } \\
\text { outros }\end{array}$ & 1963 \\
\hline 2 & A morte de Ivan llitch & Liev Tolstói & $\begin{array}{l}\text { Ana Wainberg e Ary de } \\
\text { Andrade }\end{array}$ & \\
\hline 3 & 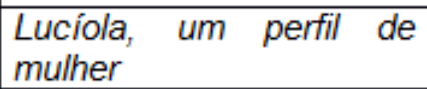 & José de Alencar & - & \\
\hline 4 & Desaforismos & Mário da Silva Brito & - & \\
\hline 5 & $\begin{array}{l}\text { Capitalismo do século } \\
\text { vinte }\end{array}$ & Eugen Varga & Luciano Martins & \\
\hline 6 & A data fatal - R.I.P. & Philip MacDonald & Azevedo Amaral & \\
\hline 7 & Poemas de amor & Castro Alves & $\begin{array}{l}\text { Introdução, seleção e } \\
\text { notas de Jamil Almansur } \\
\text { Haddad }\end{array}$ & \\
\hline 8 & $\begin{array}{lll}\begin{array}{l}\text { Memórias } \\
\text { trapaceiro }\end{array} & \text { de } & \text { um } \\
\end{array}$ & Sacha Guitry & Osório Borba & \\
\hline 9 & A metamorfose & Franz Kafka & Brenno Silveira & \\
\hline 10 & Noite na taverna & Álvares de Azevedo & - & \\
\hline 11 & A cidade e as serras & Eça de Queiroz & $\begin{array}{l}\text { Apresentação } \\
\text { Adonias Filho }\end{array}$ & \\
\hline 12 & O mandarim & Ecca de Queiroz & - & \\
\hline 13 & As minas de Salomão & Henry Rider Haggard & $\begin{array}{l}\text { Eça de Queiroz (revisão } \\
\text { da tradução) }\end{array}$ & \\
\hline 14 & A filha do capitão & A. S. Puchkin & $\begin{array}{ll}\text { Leontina Vassilieva } & \text { e } \\
\text { Renard Perez } & \end{array}$ & \\
\hline 15 & Nossa vida com papai & Clarence Day & Geir|Campos & \\
\hline 16 & A relíquia & Ecca de Queiroz & - & \\
\hline 17 & Quem perde ganha & Graham Greene & Brenno Silveira & \\
\hline 18 & Contos & Machado de Assis & \begin{tabular}{|lr} 
Apresentação de & M. \\
Cavalcanti Proença
\end{tabular} & \\
\hline
\end{tabular}




\begin{tabular}{|c|c|c|c|c|}
\hline 19 & A verdade de cada dia & Carlos Heitor Cony & - & \\
\hline 20 & Silas Marner & $\begin{array}{l}\text { George Eliot (Mary } \\
\text { Ann Evans) }\end{array}$ & $\begin{array}{ll}\text { Brenno } & \text { Silveira; } \\
\text { apresentação de Fausto } \\
\text { Cunha }\end{array}$ & \\
\hline 21 & O profeta & Gibran Khalil Gibran & Mansour Challita & \\
\hline 22 & O demônio do meio-dia & Ursula Curtiss & \begin{tabular}{lll} 
Helena & \multicolumn{2}{c}{ Pessoa; } \\
apresentação de & Alex \\
Viany & &
\end{tabular} & \\
\hline 23 & $\begin{array}{lll}\text { emblema rubro da } \\
\text { coragem }\end{array}$ & Stephen Crane & Brenno Silveira & \\
\hline 24 & O Ateneu & Raul Pompeia & $\begin{array}{ll}\text { Apresentação } & \text { de } \\
\text { Astrojildo Pereira } & \end{array}$ & \\
\hline 25 & Os sete enforcados & Leonid Andreiev & $\begin{array}{l}\text { Anna Weinberg; } \\
\text { apresentação de Boris } \\
\text { Schnaiderman }\end{array}$ & \\
\hline 26 & A máscara de Dimitrios & Eric Ambler & $\begin{array}{l}\text { Fernando de Castro } \\
\text { Ferro; apresentação de } \\
\text { Alex Viany }\end{array}$ & \\
\hline 27 & $\begin{array}{l}\text { O médico e o monstro e } \\
\text { outras histórias }\end{array}$ & $\begin{array}{ll}\text { Robert } & \text { Louis } \\
\text { Stevenson } & \end{array}$ & \begin{tabular}{|lll} 
Helena & Pessoa; \\
apresentação & de & Mario \\
da Silva Brito & & \\
\end{tabular} & \\
\hline 28 & Meu tio Benjamin & Claude Tillier & $\begin{array}{l}\text { Osório } \\
\text { apresentação de Parba; } \\
\text { Rónai }\end{array}$ & \\
\hline 29 & Cândido ou o otimismo & Voltaire & Miécio Tati & \multirow[t]{12}{*}{1964} \\
\hline 30 & A morte de um fantasma & Margery Allingham & $\begin{array}{l}\text { Fernando de } \\
\text { Ferro }\end{array}$ & \\
\hline 31 & Iracema: lenda do Ceará & José de Alencar & $\begin{array}{l}\text { Apresentação de Jamil } \\
\text { Almansur Haddad }\end{array}$ & \\
\hline 32 & A tragédia de minha vida & Oscar Wilde & $\begin{array}{l}\text { Zuleide Faria de Melo; } \\
\text { apresentação de Mario } \\
\text { da Silva Brito }\end{array}$ & \\
\hline 33 & Rubayat & Omar Khayyam & $\begin{array}{l}\text { Trad. e notas de Jamil } \\
\text { Almansur Haddad (texto } \\
\text { de Fitzgerald) }\end{array}$ & \\
\hline 34 & $\begin{array}{lcl}\text { Memórias de um } & \text { um } \\
\text { sargento de milícias } & \end{array}$ & $\begin{array}{l}\text { Manuel Antônio de } \\
\text { Almeida }\end{array}$ & - & \\
\hline 35 & Dom Casmurro & Machado de Assis & $\begin{array}{lcc}\text { Apresentação de } & \text { M. } \\
\text { Cavalcanti Proença }\end{array}$ & \\
\hline 36 & A sucessora & Carolina Nabuco & - & \\
\hline 37 & $\begin{array}{l}\text { O que devemos } \\
\text { conhecer de moeda e } \\
\text { crédito, preços e bancos }\end{array}$ & Luiz Souza Gomes & - & \\
\hline 38 & Contos húngaros & Vários autores & \begin{tabular}{lrr} 
Seleção, & \multicolumn{2}{c}{ tradução, } \\
apresentação e & notas \\
biográficas de & Paulo \\
Rónai; revisão & de \\
Aurélio Buarque & de \\
Holanda Ferfeira & \\
\end{tabular} & \\
\hline \multicolumn{4}{|r|}{ 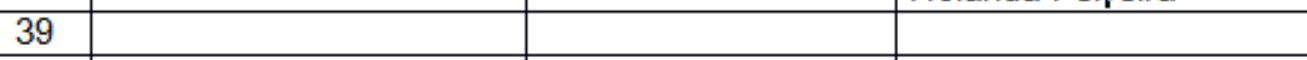 } & \\
\hline 40 & $A$ arte de amar & Ovídio & $\begin{array}{l}\text { Trad., apresentação e } \\
\text { notas de Jamil Almansur } \\
\text { Haddad; (Dúnia Marinho } \\
\text { da Silva ???) }\end{array}$ & \\
\hline
\end{tabular}




\begin{tabular}{|c|c|c|c|c|}
\hline 41 & $\begin{array}{l}\text { Nosso } \\
\text { Havana }\end{array}$ homem em & Graham Greene & Brenno Silveira & \\
\hline 42 & $\mathrm{O}$ americano tranquilo & Graham Greene & Brenno Silveira & \\
\hline 43 & A rosa tatuada & Tennessee Williams & $\begin{array}{l}\text { R. Magalhães Júnior } \\
\text { (trad. e apresentação) }\end{array}$ & \\
\hline 44 & $\begin{array}{l}\text { O homem que matava } \\
\text { quadros }\end{array}$ & Luiz Lopes Coelho & - & \\
\hline 45 & $\begin{array}{l}\text { Vocabulário ortográfico } \\
\text { oficial }\end{array}$ & $\begin{array}{l}\text { Walmírio Eronides de } \\
\text { Macedo }\end{array}$ & - & \\
\hline 46 & O retrato de Dorian Gray & Oscar Wilde & Lígia Junqueira & \multirow[t]{10}{*}{1965} \\
\hline 47 & $\begin{array}{l}\text { Guia de alimentação } \\
\text { infantil }\end{array}$ & Rachel Horowicz & - & \\
\hline 48 & Madame Bovary & Gustave Flaubert & Nair Lacerda & \\
\hline 49 & A dama das camélias & $\begin{array}{l}\text { Alexandre Dumas } \\
\text { Filho }\end{array}$ & Rubens Stuckenbruck & \\
\hline 50 & $\begin{array}{l}\text { A responsabilidade } \\
\text { sexual da mulher }\end{array}$ & Maxine Davis & Dra. Guiomar Fedner & \\
\hline 50 & $\begin{array}{l}\text { Aprenda desenho - } \\
\text { noções de desenho para } \\
\text { principiantes }\end{array}$ & Edmundo Rodrigues & - & \\
\hline 51 & Estórias rudes & Charles Astor & $\begin{array}{l}\text { Apresentação de Paulo } \\
\text { Rónai }\end{array}$ & \\
\hline \multicolumn{4}{|r|}{ Not } & \\
\hline 53 & $\begin{array}{llr}\text { Jardins } & \text { - pequenos } \\
\text { jardins, } & \text { jardins } & \text { em } \\
\text { terraços, } & \text { plantas } & \text { em } \\
\text { vasos e jardineiras } & \\
\end{array}$ & $\begin{array}{l}\text { Leonam de Azevedo } \\
\text { Pena }\end{array}$ & - & \\
\hline $53-\mathrm{A}$ & $\begin{array}{l}\text { Hortas - pequenas } \\
\text { hortas residenciais }\end{array}$ & $\begin{array}{l}\text { Leonam de Azevedo } \\
\text { Pena }\end{array}$ & - & \\
\hline \multicolumn{5}{|c|}{ 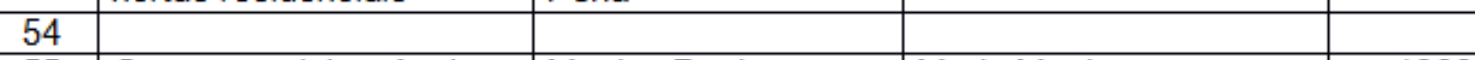 } \\
\hline 55 & $\begin{array}{l}\text { Sexo e adolescência - } \\
\text { guia para os jovens e } \\
\text { seus pais }\end{array}$ & Maxine Davis & Maria Muniz & \multirow[t]{4}{*}{1966} \\
\hline 55 & $\begin{array}{l}\text { Gramática popular da } \\
\text { língua portuguesa }\end{array}$ & Walmírio de Macedo & - & \\
\hline 56 & O homem invisivel & H. G. Wells & Monteiro Lobato & \\
\hline 57 & Um ramo para Luísa & José Condé & - & \\
\hline 58 & $\begin{array}{l}\text { A vida fantástica dos } \\
\text { Beatles - "Me ama, tá?" }\end{array}$ & Michael Braun & $\begin{array}{ll}\text { Augusto } & \text { Newton } \\
\text { Goldman } & \\
\end{array}$ & 1967 \\
\hline 59 & O repouso do guerreiro & Christiane Rochefort & Barreto Borges & \multirow[t]{4}{*}{1966} \\
\hline 60 & A comédia humana & William Saroyan & Alex Viany & \\
\hline 61 & O masoquismo & Dr. S. Nacht & & \\
\hline 62 & $\begin{array}{l}\text { loga para cristãos em } \\
\text { dez lições }\end{array}$ & Jean Marie Dechanet & M. L. Albuquerque & \\
\hline 63 & $\begin{array}{lll}O & \text { simples } & \text { Coronel } \\
\text { Madureira } & \\
\end{array}$ & Marques Rebelo & - & \multirow[t]{3}{*}{1967} \\
\hline 64 & Psicoterapia de grupo & $\begin{array}{l}\text { S. H. Foulkes e E. J. } \\
\text { Anthony }\end{array}$ & Roberto Pontual & \\
\hline 65 & & & & \\
\hline
\end{tabular}




\begin{tabular}{|c|c|c|c|c|}
\hline 66 & $\begin{array}{l}\text { A herdeira (Washington } \\
\text { Square) }\end{array}$ & Henry James & $\begin{array}{llr}\text { Berenice } & & \text { Xavier; } \\
\text { prefácio de } & \text { Paulo } \\
\text { Franpis }\end{array}$ & \\
\hline \multicolumn{4}{|r|}{ ( } & \\
\hline 68 & $\begin{array}{l}\text { Aprenda a desenhar o nu } \\
\text { artístico }\end{array}$ & Edmundo Rodrigues & - & \\
\hline 69 & $\begin{array}{l}\text { O cérebro de Einstein - } \\
\text { contos insólitos }\end{array}$ & Josef Nesvadba & & \\
\hline 70 & $\begin{array}{lrl}\text { A } & \text { psicologia do } \\
\text { aprendizado } & & \\
\end{array}$ & $\begin{array}{l}\text { Robert Borger e A. E. } \\
\text { M. Seaborne }\end{array}$ & Vera Borda & \\
\hline 71 & $\begin{array}{l}\text { Da próxima vez o fogo: } \\
\text { racismo nos EUA }\end{array}$ & James Baldwin & $\begin{array}{ll}\text { Christiano } & \text { Monteiro } \\
\text { Oiticica } & \end{array}$ & \\
\hline 72 & O obelisco negro & $\begin{array}{ll}\text { Erich } & \text { Maria } \\
\text { Remarque } & \\
\end{array}$ & Brenno Silveira & \\
\hline 73 & $\begin{array}{l}\text { Estranha gente mora no } \\
\text { Rio (das memórias de } \\
\text { um policial) }\end{array}$ & $\begin{array}{ll}\text { Fernando } & \text { Bastos } \\
\text { Ribeiro } & \end{array}$ & (2) & \\
\hline 74 & Mao Tsé-Tung & Stuart Schram & Maria Helena Kühner & \multirow[t]{7}{*}{1968} \\
\hline 75 & Lolita & Vladimir Nabokov & Brenno Silveira & \\
\hline 76 & Os sentidos & Otto Lowenstein & $\begin{array}{l}\text { Mário Antonio Coelho da } \\
\text { Silva }\end{array}$ & \\
\hline \multicolumn{4}{|l|}{77} & \\
\hline \multicolumn{4}{|l|}{78} & \\
\hline 79 & $\begin{array}{l}\text { O ego e os mecanismos } \\
\text { de defesa }\end{array}$ & Anna Freud & Ȧlvaro Cabral & \\
\hline 80 & $\begin{array}{l}\text { Psicologia do ego e o } \\
\text { problema de adaptação }\end{array}$ & Heinz Hartmann & Älvaro Cabral & \\
\hline
\end{tabular}

Fonte: elaborado pelos autores. ${ }^{8}$

\section{CONSIDERAÇÕES FINAIS}

Segundo o Dicionário do livro, de Faria e Pericão (2008), coleção é um grupo de publicações distintas, ligadas entre si por um título comum, cada uma com o seu título próprio e seu responsável, expresso ou não. A coleção em si tem o seu responsável, singular ou coletivo, pode ser ou não numerada e, ainda, ser subdividida em subcoleções, com numeração própria ou apenas a numeração da coleção em que se insere. Obedece, em geral, a regras editoriais que regem o formato, a capa, as ilustrações, o número de pesquisas, a impressão de um conjunto de textos sobre temas considerados homogêneos pelo editor. (Faria e Pericão, 2008).

A BUP, portanto, publicou uma grande coleção reunida sob o critério do formato, numerada (é possível conhecer uma série pela lista publicada ao final de alguns títulos), mas subdividida em séries ou subcoleções. A semelhança que emparelha os volumes está ligada ao projeto gráfico geral da coleção e à estratégia de manter preços abaixo da média de mercado, na comparação com outras casas editoriais brasileiras. Tratava-se de uma coleção de editor ou editorial que, embora tenha durado apenas cinco anos e publicado cerca de 80 títulos, pode ter servido de referência para editoras brasileiras de décadas posteriores que também se dedicaram a publicar coleções de bolso, como a L\&PM (pocket), sem dúvida a mais bem-sucedida entre elas. Tal êxito provavelmente foi a inspiração para que a Companhia das Letras criasse a Companhia de Bolso e a extinta Cosac Naify, a coleção Portátil, tempos depois. 


\section{REFERÊNCIAS}

Calasso, R. (2014). La marca del editor. Barcelona: Anagrama.

Carvalho, M. M. C. e Almeida Toledo, M. R. (2004). A coleção como estratégia editorial de difusão de modelos pedagógicos: o caso da Biblioteca de Educação, organizada por Lourenço Filho. In I Seminário Brasileiro Sobre Livro E História Editorial, Rio de Janeiro, Casa de Rui Barbosa, Anais... 8 a 11 nov.

Castro, C. A. (2005). Produção e circulação de livros no Brasil: dos jesuítas (1550) aos militares (1970). Encontros Bibli: revista eletrônica de biblioteconomia e ciência da informação, 10(20), 92-103. Recuperado de https://perio dicos.ufsc.br/index.php/eb/article/view/1518-2924.2005v10n20p92/305

Chartier, R. (2004). Leituras e leitores na França do Antigo Regime. São Paulo: Editora Unesp.

Correio da Manhã. (1963). Recuperado de http://memoria.bn.br/DocReader/089842_07/42005.

El Far, A. (2006). O livro e a leitura no Brasil. Rio de Janeiro: Jorge Zahar.

Faria, M. I. e Pericão, M. G. (2008). Dicionário do livro. Da escrita ao livro eletrônico. São Paulo: Edusp.

García Canclini, N. (2013). Culturas hibridas. Estratégias para entrar e sair da modernidade. São Paulo: Edusp.

Hallewell, L. (2005). O livro no Brasil. Sua história. São Paulo: Edusp.

Larraz, F. (2009). Política y cultura. Biblioteca contemporánea y Colección Austral, dos modelos de difusión cultural. Orbis tertius, 14(15), 1-11. Recuperado de https://www.orbistertius.unlp.edu.ar/article/view/OTv14n15d01

Sánchez Ortega, J. J. (2013). La modalidad paratextual: teorías y aplicaciones narratológicas en la confección del libro de bolsillo (I). Philologica Urcitana: revista semestral de iniciación a la investigación en filología, 9, 103-129. Recuperado de http://repositorio.ual.es/handle/10835/3026

Satué, E. (2004). Aldo Manuzio. Editor. Tipógrafo. Livreiro. O design do livro do passado, do presente e, talvez, do futuro. Cotia, SP: Ateliê Editorial.

Souza, W. E. R. e Crippa, G. (2014). A diversificação e popularização do livro e o surgimento e desenvolvimento de coleções de bolso no Brasil. Revista FAMECOS, 21(1), 186-207. Recuperado de http://revistaseletronicas.pucr s.br/ojs/index.php/revistafamecos/article/view/14486/11330

\section{Notas}

1 Parece-nos no mínimo honesto lembrar que muitas inferências sobre o Brasil, em qualquer época, tomam parte do país (que sabemos ter dimensão continental e muita desigualdade) como o todo. Certa produção cultural e editorial hegemônica não é igualitariamente distribuída, sequer como item de consumo. O Brasil ainda conta com poucas livrarias e mesmo bibliotecas, situação agravada pela concentração, em algumas regiôes, das existentes.

2 Souza e Crippa (2014) mencionam iniciativas isoladas, muito episódicas e sem sucesso, entre os anos 1870 e 1930.

3 A coleção "Primeiros Passos" é de ensaios introdutórios, prioritariamente para o público universitário. Não se inclui entre coleções literárias.

4 Chartier (2004) lembra a história da Biblioteca Azul, na França do início do século XVII, quando o impressor Nicolas Oudot deu início à produção de livros com papel azul de baixa qualidade, usando pranchas já utilizadas, tipos já gastos e formando um catálogo de obras bastante díspares (novelas de cavalaria, vidas de santos e outros). A percepção de que esses livros pequenos e "populares" são de menor qualidade é, portanto, de origem antiga.

5 O tipo que conhecemos amplamente, hoje em dia, como itálico tinha os nomes de aldino, chanceler, cursivo e, mais tarde, grifo. Provavelmente, este último nome diz respeito ao gravador desses tipos, Francesco Griffo, também italiano (Satué, 2004).

6 Para mais informação sobre esta impressionante coleção, ver Larraz (2009). Para aprofundamentos sobre coleções, ver Carvalho e Toledo (2004) e Sánchez Ortega (2013).

7 Conforme dados disponíveis em (https://www.livredepoche.com/page/historique-du-livre-de-poche). Acesso em: 31 mar. 2019.

8 Encontramos outros quatro títulos pertencentes à coleção, sem, no entanto, poder identificar o correspondente número do volume. São eles: Thalassa - Psicanálise das origens da vida sexual, Dr. Sandor Ferenczi, trad. Wagner Martins Lopes, 1967; O bem estar fisico das crianças, Audrey Kelly, trad. Vera Borda, 1967; Um guarda-chuva para o coronel, Joel Silveira, 1968 [s.n.]; e O sexo perigoso - o mito da maldade feminina, Hoffman Reynolds Hays, trad. Leo Pontual, 1968 [s.n.], 
ana Elisa Ribeiro, et al. Coleções de livros de bolso no Brasil: notas sobre a Biblioteca Univer...

sendo que os dois últimos, curiosamente, foram publicados no formato 14 x $21 \mathrm{~cm}$, fugindo, portanto, ao formato padrão dos livros de bolso.

\section{BY-NC-SA}

